UDC 616.1

DOI: 10.21668/health.risk/2020.2.07.eng

\title{
STRUCTURAL PECULIARITIES OF METABOLIC SYNDROME IN WORKERS EMPLOYED AT OIL EXTRACTING ENTERPRISE
}

\section{A.E. Nosov, E.M. Vlasova, A.S. Baidina, O.Yu. Ustinova}

Federal Scientific Center for Medical and Preventive Health Risk Management Technologies, 82 Monastyrskaya Str., Perm, 614045, Russian Federation

Our research goal was to establish prevalence and structure of metabolic syndrome in workers employed at an oilextracting enterprise and peculiarities of a relation between working experience and metabolic syndrome components as well as medical behavior of workers given that there were cardiovascular risk factors.

Data and methods. We examined 292 oil and gas extraction operators (test group) who were exposed to adverse industrial factors (chemical factor, noise, labor hardness, and unfavorable microclimate) and 65 office workers employed at the same enterprise (reference group). We determined whether workers had metabolic syndrome components and if yes, which ones (arterial hypertension, abdominal obesity, dyslipidemia, improper glycemia on an empty stomach); we also examined a relation between working experience and probability of these components being detected in a worker.

Results. Arterial hypertension syndrome was registered in $44.9 \%$ oil and gas extraction operators and in $36.9 \%$ office workers ( $R R=1.22(95 \%$ CI 0.86-1.71)); abdominal obesity was detected in 53.8\% workers in the test group and $50.8 \%$ office workers from the reference group ( $R R=1.06$ (95\% CI 0.82-1.38)); dyslipidemia was registered in $59.6 \%$ and in $58.5 \%$ workers accordingly $(R R=1.02(95 \%$ CI 0.81-1.27)). Carbohydrate metabolism disorders were registered in $18.2 \%$ oil and gas extraction operators and in $12.3 \%$ office workers (RR $=1.45$ (95\% CI 0.72-2.89)). We detected dependence between probable AH occurrence and working experience in oil and gas extraction operators $\left(b_{0}=-2.5 ; b_{1}=0.09 ; F=1,224.3\right.$; $\left.R^{2}=0.83 ; p=0.0001\right)$ with a significant relation between the disease and working experience under exposure to adverse industrial factors; whereas there was no such dependence detected for office workers from the reference group. Dependency of abdominal obesity, dyslipidemia, and hyperglycemia on working experience was also more significant among oil and gas extraction operators $\left(R^{2}=0.43-0.56 ; p=0.0001\right)$ than among office workers $\left(R^{2}=0.11-0.52 ; p=0.02-0.0001\right)$. There was a greater \% of smokers among oil and gas extraction operators, they tended to have higher systolic, diastolic, and pulse arterial pressure. Workers didn't receive hypotensive and hypolipidemic medications in sufficient number of cases but office workers managed to achieve normal blood pressure 2.5 times more frequently.

Key words: oil-extracting enterprise, adverse industrial factors, metabolic syndrome, obesity, arterial hypertension, working experience, work-related pathology.

At the end of the $20^{\text {th }}$ century there was a significant growth in morbidity and mortality caused by cardiovascular pathologies all over the world. Predictive value of certain factors that could cause chronic non-communicable pathologies (including cardiovascular ones) was scientifically substantiated at the turn of the century and it allowed overcoming this negative ascending trend in mortality and morbidity $[1,2]$. Over the last 15 years total mortality in Russia clearly tends to decline (from $16.1 \%$ in 2005 to $12.4 \%$ in 2018); mortality among employable population follows the same trend going down from $8.3 \%$ in 2005 to $4.8 \%$ in 2018 . Over $2000-2018$ mortality caused by cardiovascular pathologies went down from $8.46 \%$ to $5.83 \% 1$. But still, in spite of overall positive trends, cardiovascular diseases still play the leading role in the structure of mortality in Russia, and achieved decrease in mortality among employable population is not enough. Diseases that contribute most into overall mortality are poly-etiologic in their essence and in some cases are also

(c) Nosov A.E., Vlasova E.M., Baidina A.S., Ustinova O.Yu., 2020

Aleksandr E. Nosov - Candidate of Medical Sciences, Head of In-patient Clinic (Therapeutic Work-related Pathology Department) (e-mail: nosov@fcrisk.ru; tel.: +7 (342) 236-87-80; ORCID: https://orcid.org/0000-0003-0539-569X).

Elena M. Vlasova - Candidate of Medical Sciences, Head of the Work-related Pathology Center (e-mail: vlasovaem@, fcrisk.ru; tel.: +7 (342) 236-85-06; ORCID: http://orcid.org/ 0000-0003-3344-3361).

Anastasiya S. Baidina - Candidate of Medical Sciences, cardiologist (Therapeutic Work-related Pathology Department) (e-mail:anastasia baidina@mail.ru; tel.: +7 (342) 236-87-60; ORCID: https://orcid.org/0000-0003-3131-5868).

Ol'ga Yu. Ustinova - Doctor of Medical Sciences, Deputy Director responsible for Clinical Work (e-mail: ustinova@fcrisk.ru; tel.: +7 (342) 236-32-64; ORCID: https://orcid.org/0000-0002-9916-5491).

\footnotetext{
${ }^{1}$ Russian annual statistical report. 2019: Statistic data collection. Rosstat. Moscow, 2019, 708 p. (in Russian).
} 
work-related [3]. Risk factors that cause their development are both traditional lifestyle ones and adverse occupational factors that at present are not being given sufficient attention [4]. Metabolic syndrome (MS) is a supra-nosologic structure that combines several most significant risk factors such as arterial hypertension $(\mathrm{AH})$, abdominal obesity (AO), improper tolerance to dextrose, increased concentration of lower density lipoproteins and triglycerides $[1,3,5]$. According to clinical recommendations, MS can be diagnosed should there be any three out of the above listed signs. An increase in number of MS components diagnosed in one patient leads to a considerable growth in risks of cardiovascular complications $[1,6]$. Workers employed at an oil-extracting enterprise are exposed to some adverse occupational factors during their work (chemical factors, noise, vibration, physical overloads, and unfavorable meteorological conditions) that can be also considered risk factors of MS and cardiovascular pathology [7-9]. At the same time, an extent to which MS components in workers employed at oil-extracting enterprises are occupationally induced has not been examined properly so far.

Our research goal was to determine prevalence and structure of metabolic syndrome in workers employed at an oil-extracting enterprise, peculiarities related to a relation between working experience and metabolic syndrome components, as well as medical behavior of workers when factors causing cardiovascular risks were present.

Data and methods. 292 oil and gas extraction operators took part in the research; their average age was $39.43 \pm 10.6$ and average duration of their working experience was $13.15 \pm 9.86$ years (test group). Our reference group (workers not exposed to adverse occupational factors) was made up of 65 supervisors and administrative workers employed at the same enterprise; their average age was $40.28 \pm 9.83$, average duration of working experience was $18.5 \pm 9.58$ years. Both groups were comparable in terms of age, working experience, lifestyle, and gender (all the examined workers were men). To perform our re- search, we divided workers from both groups into sub-groups according to duration of their working experience (shorter than 10 years; 10 years and longer).

Working conditions for workers who directly deal with collecting well production and preliminary oil treatment involve combined exposure to in-plant noise, adverse chemicals, and such unfavorable factors as labor hardness and adverse microclimate. Adverse chemicals occurring at a workplace predominantly belong to 2-4 hazard categories (oil and its components and hydrogen sulfide).

When technological operations are being performed, certain chemicals are emitted into working area air; prevailing ones are aliphatic saturated hydrocarbons $\mathrm{C}_{1-10}$ (recalculated as per C) but their levels do not exceed hygienic standards. Besides, dihydrosulfide also occurs in working are air with its concentrations being by $0.5-1.9 \mathrm{mg} / \mathrm{m}^{3}$ higher than it is acceptable (working conditions category as per its hazard is 3.1-3.2). Noise reaches $87-88 \mathrm{dBA}$ at workplaces of oil and gas extraction operators and it is by 7-8 dBA higher that the maximum permissible level (hazard category is 3.1). Labor hardness occurs due to necessity to maintain a fixed pose during $60 \%$ out of the total working time and to cover long distances (more than $8 \mathrm{~km}$, hazard category is $3.1-3.2$ ). Overall assessment of labor process allows assigning it into 3.2-3.3 hazard category.

Overall, as per results of special assessment of working conditions (SAWC) that took place the at examined enterprise in 2015 it was established that oil and gas extraction operators had to work under hazardous conditions according to the Guide ${ }^{2}$ and it applied to $100.0 \%$ working places of workers from our test group.

Workers were examined by a cardiologist according to conventional procedures. Blood pressure (BP) was taken with Little doctor tonometer and auscultatory method with measuring precision being up to $2 \mathrm{~mm} \mathrm{Hg}$, twice, with a 5-minute interval between measuring; a patient was sitting during the procedure. Average of two measurements was taken for

\footnotetext{
${ }^{2}$ G 2.2.2006-05. Guide on hygienic assessment of occupational and labor process factors. Criteria and classification of working conditions / approved by G.G. Onitshcenko, the Head of the Federal Service for Surveillance over Consumer Rights Protection and Human Well-being and the RF Chief Sanitary Inspector on July 29, 2005, 142 p. (in Russian).
} 
analysis. Systolic blood pressure equal to $140 \mathrm{~mm}$ $\mathrm{Hg}$ and higher and diastolic blood pressure equal to $90 \mathrm{~mm} \mathrm{Hg}$ and higher was considered increased blood pressure. Waist circumference was measured at navel high at the middle point between the upper edge of the flank bone and the lower edge of the costal margin. Waist circumference exceeding $94 \mathrm{~cm}$ was considered increased. We determined dextrose concentration on an empty stomach (concentration equal to $6.1 \mathrm{mmol} / \mathrm{L}$ and higher was considered increased), cholesterol of low density lipoproteins (concentration equal to $3.0 \mathrm{mmol} / \mathrm{L}$ and higher was considered increased), cholesterol of high density lipoproteins (concentration equal to $1.0 \mathrm{mmol} / \mathrm{L}$ and lower was considered decreased), and triglycerides (concentration equal to $1.7 \mathrm{mmol} / \mathrm{L}$ and higher was considered increased) according to conventional biochemical procedures. Should any parameter in this lipidogram deviate from its physiological standard, we diagnosed dyslipidemia in a worker.

We applied the following diagnostic criteria to determine whether a worker had MS.

The basic criterion was:

- central (abdominal) obesity that became apparent via waist circumference (WC) exceeding $80 \mathrm{~cm}$ in women and $94 \mathrm{~cm}$ in men;

Additional criteria were:

- BP (blood pressure $\geq 140 / 90 \mathrm{~mm} \mathrm{Hg}$ );

- increased triglycerides concentration $\geq 1,7 \mathrm{mmol} / \mathrm{L}$;

- a decrease in cholesterol of high density lipoproteins $(\leq 1.0 \mathrm{mmol} / \mathrm{L}$ in $\mathrm{men} ;<1.2 \mathrm{mmol} / \mathrm{L}$ in women);

- an increase in cholesterol of low density lipoproteins $\geq 3.0 \mathrm{mmol} / \mathrm{L}$;

- hyperglycemia on an empty stomach (dextrose in blood plasma on an empty stomach is $\geq 6.1 \mathrm{mmol} / \mathrm{L}$ );

- improper tolerance to dextrose (dextrose in blood plasma is within $>7.8$ and $<11.1 \mathrm{mmol} / 1$ 2 hours after tolerance to it was tested).

In case a patient had central obesity and two other criteria or three any criteria out of the above mentioned ones, MS diagnosis was well substantiated $[3,10]$.
We statistically processed all the data with specialized software developed by the Federal Scientific Center for Medical and Preventive Health Risk Management Technologies. Qualitative binary signs were assessed with exact Fischer's test, relative risk calculation, and confidence interval (the results were given as (95\% CI). Quantitative signs were compared as per Student's t-test $(t>0.2)$ with statistical significance being equal to $0.05(p<0.05)$.

To substantiate response markers, we built up models for dependence between a probability of deviation in a parameter and working experience. Models were built separately for each response parameter via non-linear logistic regression analysis that allowed assessing parameters of a model given with the following formula (1):

$$
p=\frac{1}{1+e^{-\left(b_{0}+b_{1} x\right)}},
$$

where $p$ is a probability that a laboratory parameter of a response deviates from its physiological standard; $x$ is working experience duration; $b_{0}, b_{1}$ are mathematical model parameters determined according to the least square method with applied software for statistical data analysis.

We performed our research in full conformity with the ICHGCP rules, ethical principles stated in Helsinki Declaration (last edited in 2008), RF National Standard GOST-R 52379-2005 «Good Clinical Practice» $(\mathrm{ICH} \text { E6 GCP })^{3}$. The research program was approved by the Ethical Committee of the Federal Scientific Center for Medical and Preventive Health Risk Management Technologies (Meeting report No. 55 dated December 20, 2018). All the workers were provided with exact information on the research goals and they all gave their voluntary informed consent to take part in it.

Results and discussion. Table 1 contains data on MS components prevalence among workers from the test and reference groups. Our research revealed that there were no statistically significant differences as per relative

\footnotetext{
${ }^{3}$ GOST-R 52379-2005. Good Clinical Practice (ICH E6 GCP): RF National Standard. KODEKS: an electronic fund for legal and reference information. Available at: http://docs.cntd.ru/document/1200041147 (13.02.2020) (in Russian).
} 
Table 1

MS components prevalence

\begin{tabular}{|c|c|c|c|}
\hline Disease & $\begin{array}{c}\text { Test group } \\
n=292\end{array}$ & $\begin{array}{l}\text { Reference group } \\
n=65\end{array}$ & $\begin{array}{c}\mathrm{RR} \\
\text { (CI } 95 \%)\end{array}$ \\
\hline \multicolumn{4}{|c|}{ Morbidity in both groups } \\
\hline Arterial hypertension, $n(\%)$ & $131(44.9)$ & $24(36.9)$ & $1.22(0.86-1.71)$ \\
\hline Carbohydrate metabolism disorders (R73.9), \% & $53(18.2)$ & $8(12.3)$ & $1.45(0.72-2.89)$ \\
\hline Abdominal obesity (E66), \% & $157(53.8)$ & $33(50.8)$ & $1.06(0.82-1.38)$ \\
\hline Dyslipidemia (E78), \% & $174(59.6)$ & $38(58.5)$ & $1.02(0.81-1.27)$ \\
\hline \multicolumn{4}{|c|}{ Morbidity among workers with working experience shorter than 10 years } \\
\hline Arterial hypertension, $n(\%)$ & $43(31.2)$ & $8(28.6)$ & $1.09(0.57-2.06)$ \\
\hline Carbohydrate metabolism disorders (R73.9), \% & $13(9.4)$ & $1(3.6)$ & $2.64(0.35-19.35)$ \\
\hline Abdominal obesity (E66), \% & $58(42.0)$ & $8(28.6)$ & $1.47(0.79-2.73)$ \\
\hline Dyslipidemia (E78), \% & $71(51.4)$ & $11(39.3)$ & $1.31(0.80-2.13)$ \\
\hline \multicolumn{4}{|c|}{ Morbidity among workers with working experience longer than 10 years } \\
\hline Arterial hypertension, $n(\%)$ & $88(57.1)$ & $16(43.2)$ & $1.32(0.89-1.96)$ \\
\hline Carbohydrate metabolism disorders (R73.9), \% & $40(25.9)$ & $7(18.9)$ & $1.37(0.67-2.82)$ \\
\hline Abdominal obesity (E66), \% & $99(64.3)$ & $25(67.6)$ & $0.95(0.74-1.23)$ \\
\hline Dyslipidemia (E78), \% & $103(66.9)$ & $27(72.9)$ & $0.91(0.73-1.15)$ \\
\hline
\end{tabular}

risks of MS components detection among oil and gas extraction operators and administrative staff. However, we should note there were still certain peculiarities in detected morbidity. AH was registered in $44.9 \%$ workers from the test group and only in $36.9 \%$ workers from the reference group $(\mathrm{RR}=1.22(95 \% \mathrm{CI}$ 0.86-1.71)). As working experience became longer, a share of people with $\mathrm{AH}$ increased from $31.2 \%$ to $57.1 \%$ in the test group, and from $28.6 \%$ to $43.2 \%$ in the reference group. Relative risk of $\mathrm{AH}$ occurrence among oil and gas extraction operators grew from RR $=1.09$ (95\% CI 0.57-2.06) with working experience shorter than 10 years to $\mathrm{RR}=1.32(95 \% \mathrm{CI} 0.89-1.96)$ with working experience longer than 10 years.

Abdominal obesity as a determining MS component was detected in $53.8 \%$ workers from the test group and in 50.8\% workers from the reference group ( $\mathrm{RR}=1.06(95 \% \mathrm{CI}$ 0.82-1.38)). As working experience became longer, a share of people with AO grew from $42.0 \%$ to $64.3 \%$ in the test group, and from $28.6 \%$ to $67.6 \%$ in the reference group. Relative risk of $\mathrm{AO}$ amounted to $1.47(95 \% \mathrm{CI}$ 0.79-2.73) for oil and gas extraction operators with their working experience being shorter than 10 years, and to 0.95 (95\% CI 0.74-1.23) for those with working experience being longer than 10 years.
Dyslipidemia was detected in $59.6 \%$ workers from the test group and $58.5 \%$ workers from the reference group $(\mathrm{RR}=1.02(95 \%$ CI 0.81-1.27)). As working experience became longer, a share of people with dyslipidemia increased from $51.4 \%$ to $66.9 \%$ in the test group, and from $39.3 \%$ to $72.9 \%$ in the reference group. Relative risk of dyslipidemia amounted to 1.31 (95\% CI 0.80-2.13) for oil and gas extraction operators with their working experience being shorter than 10 years, and to 0.91 (95\% CI 0.73-1.15) for those with working experience being longer than 10 years.

Carbohydrate metabolism disorders (hyperglycemia on an empty stomach) were detected in $18.2 \%$ workers from the test group and $12.3 \%$ workers from the reference group $(R R=1.45$ (95\% CI 0.72-2.89)). As working experience became longer, a share of people with hyperglycemia on an empty stomach increased from $9.4 \%$ to $25.9 \%$ in the test group, and from $3.6 \%$ to $18.9 \%$ in the reference group. Relative risk of hyperglycemia on an empty stomach amounted to $2.64(95 \% \mathrm{CI}$ 0.35-19.35) for oil and gas extraction operators with their working experience being shorter than 10 years, and to $1.37(95 \% \mathrm{CI}$ 0.67-2.82) for those with working experience being longer than 10 years.

The next stage in our work involved assessing MS structure as per a number of MS 
components (comorbidity) detected in each examined worker employed at the enterprise (Table 2). There was a bit lower share of workers without any MS components or having only 1 among oil and gas extraction operators $(\mathrm{RR}=0.76(95 \%$ CI $0.46-1.26)$ and $\mathrm{RR}=0.89$ (95\% CI 0.58-1.36) accordingly). However, relative risk of 2 or 3 components occurring in a worker tended to grow in the test group and amounted to $\mathrm{RR}=1.46$ (95\% CI 0.82-2.59) and $\mathrm{RR}=1.11(95 \%$ CI 0.67-1.85) accordingly. Relative risk of detecting all $4 \mathrm{MS}$ components was a bit lower for workers from the test group $(\mathrm{RR}=0.85(95 \%$ CI 0.36-2.01)). Complete MS (3 or more components) was diagnosed in $31.8 \%$ oil and gas extraction operators and in $30.8 \%$ administrative workers $(\mathrm{RR}=1.04$ (95\% CI 0.69-1.55)).

We analyzed and compared comorbidity with MS components in groups with different working experience and revealed that workers from the test group with their working experience being shorter than 10 years ran lower rela- tive risk of $\mathrm{MS}$ components absence $(\mathrm{RR}=0.63$ (95\% CI 0.38-1.04). However, a relative risk that $1 \mathrm{MS}$ component occurred amounted to $\mathrm{RR}=1.17(95 \% \mathrm{CI} 0.62-2.19)$ in the test group; relative risk of 2 components occurring amounted to $\mathrm{RR}=1.96$ (95\% CI 0.64-5.99). The greatest number of MS components among workers with short working experience was revealed in the test group only, $2.9 \%$ cases against $0 \%$ in the reference group. Relative risk of MS components absence or only 1 component occurring amounted to $\mathrm{RR}=1.12(95 \% \mathrm{CI}$ 0.34-3.70) and $\mathrm{RR}=0.66(95 \%$ CI $0.36-1.18)$ accordingly among workers from the test group with their working experience exceeding 10 years. At the same time, relative risk of comorbidity ( 2 or 3 components occurring) amounted to $\mathrm{RR}=1.29(95 \% \mathrm{CI} 0.67-2.51)$ and $\mathrm{RR}=1.28$ (95\% CI 0.69-2.38) accordingly for the same workers. Comorbidity with 4 MS components was detected in $12.3 \%$ workers from the test group, and $16.2 \%$ workers from the reference group $(\mathrm{RR}=0.76(95 \% \mathrm{CI} 0.33-1.77)$.

Table 2

Comorbidity with metabolic syndrome components

\begin{tabular}{|l|c|c|c|}
\hline \multicolumn{1}{|c|}{ Number of components } & $\begin{array}{c}\text { Test group } \\
n=292\end{array}$ & $\begin{array}{c}\text { Reference group } \\
n=65\end{array}$ & $\begin{array}{c}\text { RR } \\
\text { CI 95 \%) }\end{array}$ \\
\hline \multicolumn{3}{|c|}{ Comorbidity with MS components in the whole groups } \\
\hline Absent, \% & $51(17.3)$ & $15(23.1)$ & $0.76(0.46-1.26)$ \\
\hline 1 component, \% & $76(26.0)$ & $19(29.2)$ & $0.89(0.58-1.36)$ \\
\hline 2 components, \% & $72(24.7)$ & $11(16.9)$ & $1.46(0.82-2.59)$ \\
\hline 3 components, \% & $70(23.9)$ & $14(21.5)$ & $1.11(0.67-1.85)$ \\
\hline 4 components, \% & $23(7.9)$ & $6(9.2)$ & $0.85(0.36-2.01)$ \\
\hline Complete MS & $93(31.8)$ & $20(30.8)$ & $1.04(0.69-1.55)$ \\
\hline \multicolumn{1}{|c|}{ Comorbidity with MS components in groups with working experience shorter than 10 years } \\
\hline Absent, \% & $37(26.8)$ & $12(42.8)$ & $0.63(0.38-1.04)$ \\
\hline 1 component, \% & $46(33.3)$ & $8(28.6)$ & $1.17(0.62-2.19)$ \\
\hline 2 components, \% & $29(21.0)$ & $3(10.7)$ & $1.96(0.64-5.99)$ \\
\hline 3 components, \% & $22(15.9)$ & $5(17.8)$ & $0.89(0.37-2.16)$ \\
\hline 4 components, \% & $4(2.9)$ & 0 & - \\
\hline Complete MS & $26(18.8)$ & $5(17.9)$ & $1.06(0.44-2.51)$ \\
\hline \multicolumn{1}{|c|}{ Comorbidity with MS components in groups with working experience longer than 10 years } \\
\hline Absent, \% & $14(9.1)$ & $3(8.1)$ & $1.12(0.34-3.70)$ \\
\hline 1 component, \% & $30(19.5)$ & $11(29.7)$ & $0.66(0.36-1.18)$ \\
\hline 2 components, \% & $43(27.9)$ & $8(21.6)$ & $1.29(0.67-2.51)$ \\
\hline 3 components, \% & $48(31.2)$ & $9(24.3)$ & $1.28(0.69-2.38)$ \\
\hline 4 components, \% & $19(12.3)$ & $6(16.2)$ & $0.76(0.33-1.77)$ \\
\hline Complete MS & $67(43.5)$ & $15(40.5)$ & $1.07(0.69-1.65)$ \\
\hline
\end{tabular}


Parameters of logistic regression

«exposure marker (working experience) - response indicator (the disease)»

\begin{tabular}{|c|c|c|c|c|c|c|c|}
\hline Exposure marker & Effect marker & $\begin{array}{l}\text { A trend in parameter } \\
\text { change }\end{array}$ & $b_{0}$ & $b_{1}$ & $F$ & $R^{2}$ & $p$ \\
\hline \multicolumn{8}{|c|}{ Test group } \\
\hline Working experience & Arterial hypertension & Ascending & -2.5 & 0.09 & 1224.3 & 0.83 & 0.0001 \\
\hline Working experience & Abdominal obesity & Ascending & -1.85 & 0.05 & 211.2 & 0.43 & 0.0001 \\
\hline Working experience & $\begin{array}{c}\text { Carbohydrate } \\
\text { metabolism disorders }\end{array}$ & Ascending & -2.59 & 0.07 & 324.7 & 0.53 & 0.0001 \\
\hline Working experience & Dyslipidemia & Ascending & -0.21 & 0.05 & 371.0 & 0.56 & 0.0001 \\
\hline \multicolumn{8}{|c|}{ Reference group } \\
\hline Working experience & Arterial hypertension & Ascending & - & - & - & - & - \\
\hline Working experience & Abdominal obesity & Ascending & -1.66 & 0.06 & 6.41 & 0.11 & 0.02 \\
\hline Working experience & $\begin{array}{c}\text { Carbohydrate } \\
\text { metabolism disorders }\end{array}$ & Ascending & -2.48 & 0.07 & 32.9 & 0.49 & 0.0001 \\
\hline Working experience & Dyslipidemia & Ascending & -1.02 & 0.13 & 58.86 & 0.52 & 0.0001 \\
\hline
\end{tabular}

We performed logistic regression analysis to examine dependence between MS components occurrence and duration of working experience in the test and reference groups: the results are given in Table 3 . We revealed statistically significant dependence between duration of working experience and $\mathrm{AH}$ probability among oil and gas extraction operators $\left(b_{0}=-2.5\right.$; $\left.b_{1}=0.09 ; F=1224.3 ; R^{2}=0.83 ; p=0.0001\right)$ and the correlation between the diseases and duration of the working experience was strong. There was no similar correlation revealed in the reference group.

Dependence between $\mathrm{AH}$ and duration of working experience was greater in the test group $\left(b_{0}=-1.85 ; b_{1}=0.05 ; F=211.2 ; R^{2}=0.43\right.$; $p=0.0001)$ than in the reference one $\left(b_{0}=-1.66\right.$; $\left.b_{1}=0.06 ; F=6.41 ; R^{2}=0.11 ; p=0.02\right)$.

Carbohydrates metabolism disorders increased statistically significantly in both groups but dependence between this diseases and duration of working experience was higher among oil and gas extraction operators $\left(b_{0}=-2.59\right.$; $\left.b_{1}=0.07 ; F=324.7 ; R^{2}=0.53 ; p=0,0001\right)$ than in the reference group $\left(b_{0}=-2.48 ; b_{1}=0.07\right.$; $\left.F=32.9 ; R^{2}=0.49 ; p=0.0001\right)$.

There was also more apparent dependence between longer working experience and dyslipidemia among oil and gas extraction operators $\left(b_{0}=-0.21 ; b_{1}=0.05 ; F=371.0 ; R^{2}=0.56\right.$; $p=0.0001)$ than among administrative workers $\left(b_{0}=-1.02 ; b_{1}=0.13 ; F=58.8 ; R^{2}=0.52\right.$; $p=0.0001)$.
Case histories of workers from the examined groups had their peculiarities; for example, $42 \%$ workers from the test group smoked whereas there were only $19 \%$ smokers in the reference group $(p=0.0001)$. By the moment the research took place $25 \%$ workers from the test group had given up smoking; $24.1 \%$, in the reference group $(p=0,83)$. On average, a worker from the test group had been smoking (or had smoked before giving it up) for 14.8 years against 12.5 years for workers from the reference group $(p=0.15)$. Workers from the test group tended to have a lot of physical activity every day $(96 \%$ in the test group against $74 \%$ in the reference group, $p=0.0003$ ).

Clinical examinations revealed that workers from the test group tended to have statistically significantly higher systolic blood pressure $(131.6 \pm 15.6 \mathrm{~mm} \mathrm{Hg}$ against $125.2 \pm 11.8 \mathrm{~mm} \mathrm{Hg}, p=0.0001)$ and diastolic one $(84.0 \pm 11.4 \mathrm{~mm} \mathrm{Hg}$ against $80.3 \pm 9.8 \mathrm{~mm} \mathrm{Hg}, p=0.007)$. Pulse pressure was also statistically significantly higher in the test group than in the reference one $(47.82 \pm 1.19 \mathrm{~mm} \mathrm{Hg}$ against $45.48 \pm 1.86$ $\mathrm{mm} \mathrm{Hg}, p=0.04)$. Pulse arterial pressure being higher than $60 \mathrm{~mm} \mathrm{Hg}$ as a parameter indicating that arterial stiffness was increased was also more frequently detected in the test group, $16.8 \%$ against $7.6 \%(p=0.01) .19 .1 \%$ workers from the test group took hypotensive medications against $16.9 \%$ workers from the reference one $(p=0.66)$. And workers from 
the reference group achieved normal blood pressure in $66.7 \%$ cases due to treatment whereas there were only $27.9 \%$ such workers in the test group $(p=0.014) .3 .5 \%$ workers from the test group permanently took statins against $2.6 \%$ workers from the reference group doing the same $(p=0.65)$.

Metabolic syndrome (MS) is a set of clinical and metabolic disorders that occur against resistance to insulin and are a most significant risk factor that causes cardiovascular complications [11].

G.A. Chumakova et al. give data on MS prevalence in the overall population in the world being $14-40 \%$ [12]. As per data provided in various papers, MS occurs in $23-25 \%$ population in the USA, and in Russia MS is diagnosed in $18.6 \%$ men who are younger than 40 and in $44.4 \%$ men aged from 40 to $55[2,12]$.

According to data provided by O.P. Rotar' et al., MS prevalence in four cities in Russia (Saint Petersburg, Orenburg, Kaliningrad, and Kursk) varied from $48.1 \%$ to $53.1 \%$. According to this research work, different MS components were registered in these cities as follows: $\mathrm{AO}$, from $63.0 \%$ to $73.4 \%$; $\mathrm{AH}$, from $58.1 \%$ to $67.3 \%$; carbohydrates metabolic disorders, from $23.0 \%$ to $49.2 \%$; dyslipidemia, from $23.6 \%$ to $58.7 \%$. A share of examined people who had at last $1 \mathrm{MS}$ component reached 86.4-93.7 \% [13]. Hwee-Soo Jeong et al. analyzed MS prevalence among workers exposed to lubricants, metals, dusts, and noise at their workplaces. The authors diagnosed MS in $19.8 \%$ workers. There were statistically significant discrepancies as per morbidity with MS obtained for workers who contacted lubricants during their work $(\mathrm{OR}=1.79 ; 95 \% \mathrm{CI}$ 1.06-3.01). The authors state that elevated MS prevalence among this occupational group occurs due to potential subclinical systemic inflammation caused by inhalation exposure to chemicals [14, 15]. Ramin Mehrdad et al. assessed MS prevalence among workers employed at a car-making plant in Iran. MS was diagnosed in relatively small share of workers: $7.3 \%$ among administrative staff; $7.9 \%$, among those dealing with hard physical labor; and $7.8 \%$ among those exposed to chemical factors; there were no statistically significant discrepancies between groups. But still, the authors revealed decreased high density lipoprotein contents in blood of workers who contacted chemicals during their work and increased diastolic blood pressure among those who dealt with hard physical labor [16]. The authors note that MS prevalence in Iran varies from $10 \%$ to $60 \%$ depending on age, sex, and a region where a person lives [17]. The discrepancies, in the authors' opinion, are due to «a healthy worker» effect, young age of workers, and periodical medical examinations being quite efficient.

M. Strauß et al. compared firefighters (exposed to physical loads and work stress) and office workers in Germany. MS prevalence amounted to $14 \%$ among firefighters whereas it was $33 \%$ among office workers [18]. At the same time, in the USA MS prevalence among office workers reaches $45 \%$ [19].

In 2012-2013 A.S. Baidina et al. examined MS prevalence among workers employed at an oil and gas extracting enterprise and revealed that it amounted to $44 \%$; $\mathrm{AH}$ was registered in $44.2 \%$; dyslipidemia, in $55.2 \%$; hyperglycemia on an empty stomach, in $20.0 \%$; hyperuricemy, in $42.0 \%$. Cardiovascular risk assessed as per SCORE scale amounted to $2.4 \pm 0.7 \%$ for oil and gas extraction operators, and to $0.85 \pm 0.30 \%$ for engineers $(p<0.001)$. The authors conclude that MS is a work-related disease for workers with this occupation $(\mathrm{EF}=36.75 \%$, average dependence between health disorder and occupation) [20].

I.I. Logvinenko et al. examined 125 men with their average age being 35.3 and revealed various MS components in $73.6 \%$ of them; $\mathrm{AO}$ was detected in $32.8 \% ; \mathrm{AH}, 23.2 \%$; hypercholesterolemia, $59.2 \%$. Combinations of these clinical signs were detected in $52.17 \%$ cases $[21,22]$.

G.G. Gimranova et al. showed that AH prevalence grew among workers employed at an oil extracting enterprise from $11.1 \%$ among those aged 20-29 to $62.7 \%$ among those older than 50 (an average value being equal to approximately $41 \%$ ). A share of people with $\mathrm{AH}$ reached $50 \%$ among workers with their working experience exceeding 10 years and $57 \%$ among those who had been working for more than 15 years. The authors showed that $\mathrm{AH}$ was to a great extent workrelated among drivers $(\mathrm{RR}=2.8 ; \mathrm{EF}=64.3 \%)$ 
and to an average extent among drilling operators $(\mathrm{RR}=1.6 ; \mathrm{EF}=37.5 \%)[8,9]$.

We established MS (3 or more components) in $31.8 \%$ oil and gas extraction operators and in $30.8 \%$ administrative workers in our research. But still, at least $1 \mathrm{MS}$ component was detected in $82.5 \%$ workers from the test group and in $76.9 \%$ workers from the reference one. MS prevalence differs significantly in all the above mentioned research works; it is probably due to different age, ethnic, and occupational groups being examined in them. Besides, different diagnostic MS criteria were likely to be applied in analysis. Overall, our data are well in line with other research works performed in Russia with their focus being MS prevalence among workers employed in oil extraction.

\section{Conclusions.}

1. There tend to be high prevalence of metabolic syndrome components among workers employed at an oil extracting enterprise (arterial hypertension, abdominal obesity, dyslipidemia, and carbohydrates metabolism disorders); this prevalence grows among workers with longer working experience under adverse working conditions. Approximately $80 \%$ oil and gas extraction operators and administrative staff had 1 or more metabolic syndrome components that led to elevated cardiovascular risks. Metabolic syndrome was registered in $1 / 3$ workers from both groups.
2. There was a more apparent cause-andeffect relation between working experience and metabolic syndrome components among oil and gas extraction operators; when it comes to arterial hypertension, such a relation was detected only in this group.

3. There were more smokers among oil and gas extraction operators than among administrative staff; they tended to have higher systolic, diastolic, and pulse arterial pressure. Hypotensive and hypolipidemic medications were not taken by all the workers who needed them in both groups but administrative workers achieved acceptable blood pressure 2.5 times more frequently than oil and gas extraction operators.

4. The obtained data indicate it is necessary to improve medical and prevention activities involving workers employed at an oil extracting enterprise; these activities should be aimed at eliminating risk factors that cause metabolic syndrome as it allows perverting cardiovascular diseases among workers who are in their pre-retirement age.

Funding. The research was performed within the Main Activities Plan adopted by the Federal scientific Center for Medical and Preventive Health Risk management Technologies for 2019.

Conflict of interests. The authors declare there is no any conflict of interests.

\section{References}

1. Boitsov S.A., Pogosova N.V., Bubnova M.G., Drapkina O.M., Gavrilova N.E., Eganyan R.A., Kalinina A.M., Karamnova N.S. [et al.]. Cardiovascular prevention 2017. National guidelines. Rossiiskii kardiologicheskii zhurnal, 2018, vol. 23, no. 6, pp. 7-122 (in Russian). DOI: 10.15829/1560-4071-2018-6-7-122

2. Braunwald's heart disease: a textbook of cardiovascular medicine. 10-th edition. In: R.O. Bonow, D.L. Mann, D.P. Zipes, P. Libby eds. 2015, 2240 p.

3. Oganov R.G., Denisov I.N., Simanenkov V.I., Bakulin I.G., Bakulina N.V., Boldueva S.A., Barbarash O.N., Garganeeva N.P. Comorbidities in practice. Clinical guidelines. Kardiovaskulyarnaya terapiya i profilaktika, 2017, vol. 16, no. 6, pp. 5-56 (in Russian). DOI: 10.15829/1728-8800-2017-6-5-56

4. Zaitseva N.V., Ustinova O.Yu., Alekseev V.B., Ulanova T.S., Vlasova E.M., Nosov A.E. Peculiarities of production-related diseases in miners employed at deep mining of chromic ores. Meditsina truda i promyshlennaya ekologiya, 2018, no. 10, pp. 6-12 (in Russian). DOI: 10.31089/1026-9428-2018-10-6-12

5. Dommermuth R., Ewing K. Metabolic Syndrome: Systems Thinking in Heart Disease. Prim Care, 2018, vol. 45, no. 1, pp. 109-129. DOI: 10.1016/j.pop.2017.10.003

6. Arnett D.K., Blumenthal R.S., Albert M.A., Buroker A.B., Goldberger Z.D., Hahn E.J., Himmelfarb C.D., Khera A. 2019 ACC/AHA Guideline on the Primary Prevention of Cardiovascular Disease: A Report of the American College of Cardiology. Circulation, 2019, vol. 140, no. 11, pp. e596-e646. DOI: 10.1161/CIR.0000000000000678

7. Bakirov A.B., Gimranova G.G. Priority areas of science in extraction of oil, petroleum refining, petrochemical industry. Meditsina truda i ekologiya cheloveka, 2016, no. 3, pp. 5-10 (in Russian). 
8. Gimranova G.G, Bakirov A.B., Urazaeva E.R., Gallyamova S.A. Cardio-vascular diseases in workers of oil-extracting basic occupations. Byulleten' VSNTS SO RAMN, 2009, no. 1, pp. 68-72 (in Russian).

9. Gimranova G.G., Bakirov A.B., Karimova L.K., Beigul N.A., Shaikhlislamova E.R. Factors and Indicators of Oil Extraction Occupational Risks. Vestnik RGMU, 2014, no. 1, pp. $72-75$ (in Russian).

10. Oganov R.G., Simanenkov V.I., Bakulin I.G., Bakulina N.V., Barbarash O.L., Boitsov S.A., Boldueva S.A., Garganeeva N.P. [et al.]. Comorbidities in clinical practice. Algorithms for diagnostics and treatment. Kardiovaskulyarnaya terapiya i profilaktika, 2019, vol. 18, no. 1, pp. 5-66 (in Russian). DOI: 10.15829/1728-8800-2019-1-5-66

11. Belenkov Yu.N., Privalova E.V., Kaplunova V.Yu., Zektser V.Yu., Vinogradova N.N., Il'gisonis I.S., Shakar'yants G.A., Kozhevnikova M.V., Lishuta A.S. Metabolic Syndrome: Development of the Issue, Main Diagnostic Criteria. Ratsional'naya farmakoterapiya v kardiologii, 2018, vol. 14, no. 5, pp. 757-764 (in Russian). DOI: 10.20996/1819-6446-2018-14-5-757-764

12. Chumakova G.A., Veselovskaya N.G., Grishchenko O.V., Ott A.V. Metabolic syndrome: challenging and unresolved issues. Rossiiskii kardiologicheskii zhurnal, 2014, vol. 107, no. 3, pp. 63-71 (in Russian).

13. Rotar' O.P., Libis R.A., Isaeva E.N., Erina A.M., Shavshin D.A., Moguchaya E.V., Kolesova E.P., Boyarinova M.A. [et al.]. Metabolic syndrome: challenging and unresolved issues. Rossiiskii kardiologicheskii zhurnal, 2012, vol. 94, no. 2, pp. 55-62 (in Russian).

14. Jeong H.S. The relationship between workplace environment and metabolic syndrome. Int. J. Occup. Environ. Med, 2018, no. 9, pp. 176-183. DOI: 10.15171/ijoem.2018.1346

15. Van Greevenbroek M.J., Schalkwijk C.G., Stehouwer C.D. Dysfunctional adipose tissue and lowgrade inflammation in the management of the metabolic syndrome: current practices and future advances. F1000Res, 2016, no. 5, pp. 1-10. DOI: 10.12688/f1000research.8971.1

16. Mehrdad R., Pouryaghoub G., Moradi M. Association between Metabolic Syndrome and Job Rank. The international journal of occupational and environmental medicine, 2018, vol. 9, no. 1, pp. 45-51. DOI: $10.15171 /$ ijoem.2018.1197

17. Hajian-Tilaki K. Metabolic syndrome and its associated risk factors in Iranian adults: A systematic review. Caspian J. Intern. Med, 2015, vol. 6, no. 2, pp. 51-61.

18. Strauß M., Foshag P., Przybylek B., Horlitz M., Lucia A., Sanchis-Gomar F., Leischik R. [et al.]. Occupation and metabolic syndrome: is there correlation? A cross sectional study in different work activity occupations of German firefighters and office workers. Diabetology \& metabolic syndrome, 2016, vol. 8, no. 1, pp. 57. DOI: 10.1186/s13098-016-0174-0

19. Baur D.M., Christophi C.A., Kales S.N. Metabolic Syndrome Is Inversely Related to Cardiorespiratory Fitness in Male Career Firefighters. Journal of Strength and Conditioning Research, 2012, vol. 26, no. 9, pp. 2331-2337. DOI: 10.1519/JSC.0b013e31823e9b19

20. Baidina A.S., Nosov A.E., Alekseev V.B. Metabolic syndrome risk factors among oil production enterprise employees. Ekologiya cheloveka, 2013, no. 12, pp. 44-47 (in Russian). DOI: 10.33396/1728-0869-2013-12-44-47

21. Logvinenko I.I., Koleda Ya.S., Ragino Yu.I., Voevoda M.I. Interrelation of leptin levels in blood and the main components of metabolic syndrome among oilmen working in the oil industry in Western Siberia. Ateroskleroz, 2015, vol. 11, no. 4, pp. 69-73 (in Russian).

22. Logvinenko I.I., Koleda Ya.S., Ragino Yu.I., Kashtanova E.V. Association of blood resistin levels and the main components of metabolic syndrome among oilmen in Western Siberia. Ateroskleroz, 2015, vol. 11, no. 2, pp. 31-36 (in Russian).

Nosov A.E., Vlasova E.M., Baidina A.S., Ustinova O.Yu. Structural peculiarities of metabolic syndrome in workers employed at oil extracting enterprise. Health Risk Analysis, 2020, no. 2, pp. 63-71. DOI: 10.21668/health.risk/2020.2.07.eng

Received: 18.05 .2020

Accepted: 04.06.2020

Published: 30.06 .2020 